\title{
Psycho-Pedagogical Conditions of Formation of Professional Creative Activity of Future Professionals
}

\author{
Uzakbayeva Sakypzhamal Askarovna ${ }^{1}$, Abeltayeva Zhanel Yertaevna ${ }^{2}$, Sadykova Ayzhan Erhanovna ${ }^{2}$ \& \\ Rysbekova R. ${ }^{3}$ \\ ${ }^{1}$ Kazakh University of International Relations and World Languages named after Ablai Khan, Kazakhstan \\ ${ }^{2}$ Kazakh National Art Academy named after T. Zhurgenov, Kazakhstan \\ ${ }^{3}$ Taldykorgan Pedagogical University named after Zhansugirov, Kazakhstan \\ Correspondence: Uzakbayeva Sakypzhamal Askarovna, Kazakh University of International Relations and World \\ Languages named after Ablai Khan, Muratbaeva street 200, 020000 Almaty, Kazakhstan. E-mail: \\ zhanat_2006@mail.ru
}

Received: February 28, 2015 Accepted: March 30, 2015 Online Published: July 28, 2015

doi:10.5539/ies.v8n8p193 URL: http://dx.doi.org/10.5539/ies.v8n8p193

\begin{abstract}
Organizational, psychological and pedagogical conditions (the position of student in the educational process, the inclusion of students in active and independent activities, the creation of a positive creative environment and psychological climate, the active use of the forms, methods, technologies, adequate formation of professional creative activity of students, features of individual creative development of students), a system of principles and pedagogical tools are the best support in the formation of professional and creative activity of the future experts in musical sphere (Malofeev \& Shmatko, 2008).
\end{abstract}

Keywords: creative activity, professional and creative activity, activities, independent activities, professional activities, creative development, creative self-development, self-realization, psychological and pedagogical conditions, external, internal conditions, creative environment

\section{Introduction}

It is possible to create certain conditions in the educational process for successful functioning of professional creative activity.

In the scientific literature there are different approaches to the definition of "condition". Thus, in the philosophical sense the condition is the environment in which a particular event or process exist and develop. In psycho-pedagogical studies some authors (Kharlamov I. F., Ushakov D. V., Nizams R. A. etc.) considered as a set of processes, relationships which necessary for the emergence, existence, development and change any object, (Rapatsevich E. S.) "subjective and objective conditions" which is in the educational process successfully realized. Objective preconditions aimed at developing students' needs for professional growth. Subjective conditions (basic, procedural) determine the personal attitudes of the teacher to his professional activities. (Matyushkin, 1972)

Several authors (Zhernov V. I., Leshner O. V. etc.) raised the issue of sufficient and pedagogical conditions. The terms of pedagogical condition mean the totality of the objective possibilities of content, forms, methods, educational environment aimed at problem solving. Pedagogical concerns only those conditions which are deliberately created in the pedagogical process and the implementation which provides the most efficient flow. We fully share the view of the authors, according to the pedagogical conditions cannot be reduced only to external circumstances; a set of objects, conditions affecting the process as well as the development of the personality in the pedagogical process is a unity of subjective and objective, internal and external, and the essence of the phenomenon (Slastenin, 2000).

There are several groups of pedagogical conditions in research performed in the area of training future teachers. Among them, some (Verbitsky A. A., Dyachenko M. I., Kandybovich L. A.) in addition to the traditional conditions (books, software, etc.) offer the use of complex techniques and forms, depending on the content and specificity of the studied material modeling the forthcoming academic work. The underscore need for specific features of the cognitive processes is a memory of the student, imagination, thought, etc., motivational, 
emotional and volitional; formation of pedagogical empathy, communication and culture of communication, the ability to self-control and self-improvement in their activities (Mamaychuk, 2001).

Slastenin V. A. and Pidkasisty P. I. believe that external conditions influencing the process of becoming a personal quality which refracted through the inner content. Because external conditions act as the circumstances and the environment, it is preparing future specialists. Internal conditions are the source of a student's mental activity, and include the orientation of the personality of its abilities and other psychological characteristics.

\section{Method}

Based on the fact that the professional creative activity serves an important qualitative feature of the individual during the development conditions, you must consider the laws of development of personality of the future specialist, organizing the whole process of forming professional creative activity of the individual in the structure of vocational teacher training. The external conditions of formation of professional creative activity of the future specialist pop music can be attributed. Psycho-pedagogical conditions of formation of professional creative activity of the future specialist pop music are domestic conditions affecting the development of the structure (Zhigoreva, 2009).

Theoretical analysis and personal experience of professional pedagogical activity allows us to identify a set of conditions providing formation of professional creative activity of the future specialist of music sphere are organizational, psychological and pedagogical conditions:

- Ensuring the subject position of the student in the educational process;

- The inclusion of students in active and independent activities;

- Creating a positive creative environment and psychological climate;

- Extensive use of forms, methods, technologies, adequate formation of professional creative activity of students;

- Consideration of the individual features of the creative development of students (Levchenko, 2008)

Providing subject position of the student in the educational process is the organizational conditions of formation of professional and creative activity of the future of pop musician, one of the important areas for training specialists in the sphere of art which stands on the formation of the student as the subject of learning and cognitive activity. The existing system of teacher education is the future teacher "as an object of mass reproduction frames, ignores it as the subject of professional mental development does not create conditions that encourage him to seek a personally significant meaning of the profession does not form as a carrier of pedagogical reflection" (Berezin \& Lisiecki, 2000). Provided humanistic orientation student is an active subject of teaching and achieves self-promotion, self-realization. This suggests that only in a subject-subject relations, equal educational cooperation and collaboration possible the harmonious development of the personality (Likhachev, 1998).

Inclusion of students in active independent activity is the organization performing a specific task in accordance with the intended purpose. The quality of vocational training depends largely on the proper organization of independent work. Formation of skills of self-sufficiency improves quality of teaching as a whole and contributes to training of future specialists to further knowledge acquisition (Guldan \& Korsun, 2000) The student receives his independent work, methodological advice on a practical training. Already here begins students' independent work where were asked some questions. Thus opportunities are created to meet the needs of the individual in self-realization (Dubrovina, 2012).

Development needs in creative self-connected with the activity, the practical manifestation of personal activity that is being transformed into socially valuable quality, characterized by the desire to express individuality in a useful activity, a combination of personal freedom and responsibility.

Analysis of scientific literature and experience allows us to identify the following stage of development value orientations of the personality of the student on the creative self-development.

In the first stage, students learn and estimate the quality of the self, that is, at this stage, there is an adaptation of students.

The second is characterized by the self-determination of the personal qualities of students in extracurricular and professional creativity.

In the third step in the creative practice students serve as entertainers, their own experience which convinced of the necessity of forming qualities of the creative activity of the person.

Certainly, at all stages the formation of value personal orientations of the student on the creative 
self-development is invaluable role teachers who contribute to the deepening of representations of students about the features of their character, needs, motivations, habits and abilities; help in the realization of their aptitudes, interests and abilities; guide students to do their self-development; introduce them with the methods and identify ways at certain qualities, etc. (Vachkov, 2004)

All this convinces us that the basis of creative self-development is an inner need, setting the individual to self-improvement in this activity. The success of the activity, its quality are caused by personal relations of man and more stable value orientation will be formed on the individual creative self-development, the conscious development of future specialists will be pop music.

Creating a positive creative environment and psychological climate involves ensuring the most comfortable environmental conditions indirectly affect the change in the level of formation of creative activity of the personality of the future specialist will be pop music. Possible positive creative environment creates an atmosphere of psychological comfort, co-creativity and empathy; intensify the emotional sphere of the personality of the student, leading to a state of creative inspiration; in the development of reflection and self-evaluation of the results of educational and creative activities in the development of intrinsic motivation, needs to communicate with the works of art of music to satisfy the moral and aesthetic interests (Korolenko, 1990).

At the heart of creativity lies demand the experience of positive emotions. Emotional learning involves the creation of a favorable atmosphere; it is characterized by the level of emotional intensity of the training content, speech communication, the presence of emotional situations in the process of communication of teachers and students. The emotional impact of the teacher to the student carried out due to the subjective vision of teacher training material content, and his impressions of an association.

A skill of the future specialist to analyze your emotional state, their behavioral responses, as self-report helps relieve psychological stress, restore emotional comfort, and rethink their own positions plays important role in providing emotional learning. The student learn to overcome difficulties, it is appropriate links positive emotions with a total of more prolonged activity (Zhigoreva, 2009) Providing emotional learning process promotes the formation of students' self-confidence and faith in their abilities.

Certainly, the creative development of the individual is impossible without the emotional and value relationship of the subject to their activity, cognition. Specificity of emotions that they do not reflect the actual objects and phenomena of the world and human relations in which these objects and phenomena needs. Through emotion processing occurs in the values and meanings of the activities of human life. Therefore, in the preparation of the performing musician, musician-teacher artistic experiences, emotions are an important tool for organizing the musical-educational process; they define the principles, content and structure of the artistic and aesthetic musical activities.

Heuristics that guide us, to help in the search for an artistic image, means of musical expression, methods of interpretation, based on the triad of "composer-performer-work", contribute to the development of the creative personality of the future specialist, develop skills of independent work, teach methods for finding and making unconventional solutions, going beyond the regulatory framework and thinking; create favorable conditions for reflecting its activities, awareness of its effectiveness and feasibility (Andronnikova, 2010).

Active use of the elements of the problem of learning technologies in the process of learning activity increases the level of autonomy of the future experts of musical sphere, develops creative and critical thinking that creates objective prerequisites for the formation and manifestation of the creative activity of the individual.

\section{Results}

The implementation of the above pedagogical conditions caused:

- The modern requirements of the information society, the analysis of the requirements for future educational qualification characteristics of educational qualification of "Bachelor";

- The selection of content elements of learning that most qualitatively consistent with the objectives of development of professional creative activity;

- Using appropriate methods, forms and means of education to effectively implement the process of formation of information and analytical skills of the future specialists and implementing effective ways to treat and evaluate their appropriate level of formation;

- The establishment of integration ties between science and professionally oriented disciplines;

- Optimal combination of traditional and student-centered learning technologies that will take into account 
the psychological and pedagogical factors and develop the creative potential of students, creating a need for further improvement in accordance with the principle of "lifelong learning" and the implementation of the principles of individualization and differentiation of instruction;

- The teaching agreement's content with the requirements of professional-oriented disciplines and requirements of educational qualification characteristics, through the integration of theoretical and practical training;

- To develop and implement an appropriate methodological support and multimedia in the learning process of natural sciences, in order to increase the effectiveness of students' independent work, etc.(Yarskaya-Smirnova, \& Romanov, 2002)

In our opinion, it is the realization of such approaches will provide favorable conditions for the formation of information and analytical skills of students in higher education and, as a consequence, to improve the level of professional creative activity of the future specialists (Archakova, 1999).

\subsection{The Analysis of Results}

After carrying out a series of experimental class sessions, aimed at the development of creative activity of teenagers underwent repeat diagnostics on all selected our criteria of creative activity. The purpose of it was to confirm the hypothesis put forward by us. The guys again were offered diagnostic techniques that we used to ascertaining stage of experimental work. The diagnostic results are presented in Table 1.

Table 1. Comparative table definition cognitive needs control and experimental classes after experimental work

\begin{tabular}{lccccc}
\hline Number of points & Level & control class & experimental class & & \\
\hline \multirow{2}{*}{ More than 15 } & & indicators class & Percent & indicators class & Percent \\
$10-14$ & High & $6 \mathrm{~h}$. & $28 \%$ & 5 ч. & $36 \%$ \\
Less than 10 & Medium & $7 \mathrm{~h}$. & $34 \%$ & 9 ч. & $64 \%$ \\
\hline
\end{tabular}

Presented in Table 1, the information suggests that the class is not in the control there were significant changes in the level of cognitive needs. In the experimental class we see a significant increase in cognitive needs (high level of $14 \%$ up to $36 \%$ ) and the lack of trained with low cognitive needs. Recall that the first stage of the diagnostic work, the number of students with low levels of cognitive demand was $50 \%$.

The special role in the formation of professional creative activity of students plays personality-oriented technologies, because they see each student as a unique individual, requiring constant attention and support in this process. In particular, the combination of modern information technology and student-centered technology creates the most favorable conditions for the formation of information and analytical abilities of students of economic specialties of high schools and improve their professional creative activity.

Thus, our analysis above discussed technology has allowed us to identify real opportunities to influence each of them on the formation of professional creative activity of students. All the foregoing allows us to formulate the psychological and pedagogical conditions to ensure favorable conditions for increasing the level of formation of creative activity of the future specialists in universities, namely:

- To create a favorable psychological climate in the study of natural sciences, by taking into account individualization, differentiation and integration of natural sciences;

- Increasing the motivation of students to master the appropriate level of professional creative activity skills and of creative activity in learning natural sciences;

- Introduction to learning natural sciences ict training, innovative teaching methods (project method, case method, and others), which create favorable conditions for enhancing students' cognitive activity and pave the way for the formation of professional creative activity skills of the future economists;

- To provide opportunities for each student to master the conditions of analytical tools necessary to meet future functional responsibilities by ensuring conditions conscious transition from algorithms to their use in non-standard tasks, which requires students to develop skills to generalize, to select and concentrate on the main issues regarding the set, picking up the necessary analytical tools in the context of its use, that is the 
appropriate level of creative activity (Matyuskin, 1972).

\section{Discussion}

Accounting features of individual creative development of students is manifested in registered individual psychological characteristics of personality, which is constructed on the basis of the learning process.

This condition contributes to the establishment of appropriate relationships, individual pace of learning and mastering the material, helps to regulate the process of interaction amateur students by means of knowledge and self-knowledge, organization and self-control, allows acquiring the experience of creative activity.

Since the formation of professional and creative activity is multifaceted, it necessitates the knowledge of the students the spirit of professional creative activity, ways of realization of creative potential of the individual. Lack of students systemic and deep knowledge of the characteristics of professional and creative activities are an obstacle in the formation of professional and creative activity. On this basis, we argue that the formation of professional creative activity of the future specialist will be most effective if the implementation of the complement of the course "Piano" and the program elective course "Music and creative workshop" (Clayburgh, 2001).

The course "Piano" is an integral part of the educational process in the preparation of students of faculties of variety, as all their subsequent professional activities will be linked to the piano: the analysis of works and work on them, the selection of the accompaniment, transposition, processing and arranging. All this presupposes good knowledge of musical instrument and a strong theoretical base. Study elective course will create favorable conditions for the formation of future specialists pop music representations of the essence of professional creativity, characteristics of creativity in future careers and prospects of using creative methods in a renewed high school.

The above organizational, psychological and pedagogical conditions of formation of professional and creative activity of the future specialist music platform must implement at compliance with the limited principles. Systematizing principles need to be based on an understanding of the principle (from Lat. Principium- beginning, base) as the core, the position in which expressed the fundamental requirements for the organization of the pedagogical process. In a logical sense principle is a fundamental concept that represents the compilation and dissemination of any provision to which it relates (Sorokoumova, 2011). According to some authors principles as an essential component of music education are considered as assumptions that reveal the essence of the purpose and objectives of music education, the nature of its content and process.

\section{Conclusion}

In our concept of principles is a necessary requirement for the organization of the process of formation of professional and creative activity of the future experts of musical sphere. Analysis of the general principles relating to education in general (Krajewski, 2002), principles of music education (Abdulin \& Kabalevsky) and keeping the essential characteristics of professional and creative activity, allows us to identify the following principles: the principle of subjectivity experience; principle of student-centered approach; principle of cognitive orientation; principle of variation; principle of emotional well-being; the principle of stimulating the activity of personality, its participation in socially useful and subjectively significant activities; the principle of unity of vocational training and vocational education; aesthetics of student's life.

The above principles provide a system that is in their holistic view, interconnection and interdependence, due to the choice of leading principles, depending on the stages of formation of professional and creative activity, as well as the presence of a backbone of the principle that unites all the elements of the system together.

Certainly, the pedagogical principles are not just for good data and unchanged. The development of life, the changing nature of public relations, science and teaching practice entails both the emergence of new principles that meet the requirements of modernity and internal movement, changing the existing traditional principles (Bityanova, 1998).

In the pedagogical process complex of conditions must be created through the implementation of the principles and pedagogical tools. In this regard, as the leading pedagogical means of professionally-creative activity of students to use: authoring, teaching methods; methodical complex; technical, audiovisual aids. These pedagogical tools help students search for personal meaning of educational activity, stimulate expression of the students' professional position, gaining their experience creatively transforming activity.

Thus, the formation of professional and creative activity can take place at the organizational, psychological and pedagogical conditions, using a system of principles and pedagogical tools that promote the efficient solution of 
this problem.

\section{References}

Andronnikova, O. O. (2010). Research of psychological factors emergence Victim Behavior of teenagers. International Journal of Academic Research, 2(3), 241-245.

Archakova, T. O. (1999). Inclusion: a challenge for the teacher [internet resource].

Berezin, S. V., \& Lisiecki, K. S. (2000). Psychology of early addiction. Samara: Samara University.

Bityanova, M. R. (1998). Organization of psychological work in the school. Moscow: Excellence (Applied Psychology in Education).

Clayburgh, Y. A. (2001). Psychology of deviant behavior: A manual for schools. Moscow.

Dubrovina, I. V. (2012). On the practical training of educational psychology [internet resource]. Psychological Science and Education PSYEDU.

Guldan, V. V., \& Korsun, A. M. (2000). Searching impressions as a factor of plunging adolescent into drugs. Problems of Addiction Journal, 4, 40-44.

Korolenko, T., \& Don, T. (1990). Seven ways to accident. Novosibirsk, The Science.

Krajewski, V. V. (2002). General bases of pedagogy. Volgograd: Classroom.

Levchenko, I. Y. (2008). Psychological help for families with children with developmental disabilities: Handbook. M.: Education.

Likhachev, B. (1998). Pedagogy course lectures. M.: "Prometheus", "Yurait".

Malofeev, N. N., \& Shmatko N. D. (2008). Integration and special education institutions: The need for change. Defectology, 2, 86-94.

Mamaychuk, I. I. (2001). Psychological care for children with special needs. St.Pb: Speech.

Matyushkin, A. M. (1972). Problem situations in thinking and learning. M.

Slastenin, V. A. (2000). Integrative trends in psychological and pedagogical education. Masters Press.

Sorokoumova, S. N. (2011). Psychological support of inclusive education of preschool children with disabilities. Author. dis ... doctor. psih.scince. N. Novgorod.

Vachkov, I. V. (2004). Healthy schoolchildren and a child with a disability. Children's Health (pp. 34-37).

Zhigoreva, M. V. (2009). Complex model of support development of preschool children with complex disorders: Monograph. Moscow: RIC M.A. Sholokhov MGGU.

\section{Copyrights}

Copyright for this article is retained by the author(s), with first publication rights granted to the journal.

This is an open-access article distributed under the terms and conditions of the Creative Commons Attribution license (http://creativecommons.org/licenses/by/3.0/). 